Check for updates

Cite this: RSC Adv., 2019, 9, 19408

\title{
Electrospun silica nanofiber mats functionalized with ceria nanoparticles for water decontamination $\uparrow$
}

\author{
Ines Zucker, (D)*abc Nadir Dizge, ${ }^{\text {ad }}$ Camrynn L. Fausey, (D) Evyatar Shaulsky, ${ }^{a}$ \\ Meng Sun (iD ${ }^{a}$ and Menachem Elimelech (D) ${ }^{a}$
}

\begin{abstract}
This study demonstrates the fabrication of nanoceria-immobilized silica nanofibers for efficient water decontamination with easy reuse and regeneration properties. Commercially-available ceria $\left(\mathrm{CeO}_{2}\right)$ nanoparticles were immobilized on electrospun silica nanofiber mats. Optimal conditions for both oxidation of model trace organic compounds (TrOCs) and hydroxyl-radical formation were determined in batch experiments with ceria nanoparticles. Kinetic experiments showed comparable oxidation rates of positively- and neutrally-charged TrOCs (95 and 98\%, respectively) by the nanofiber composites at $\mathrm{pH}$ 2 in $0.5 \mathrm{mM} \mathrm{H}_{2} \mathrm{O}_{2}$. We demonstrated the reuse properties of the ceria nanofiber composites, finding less than a $15 \%$ reduction in oxidation performance after 10 cycles. In addition to this oxidative performance, the electrospun $\mathrm{CeO}_{2}$ nanofiber composites are also applicable for adsorbing the persistent contaminant perfluorooctanesulfonic acid (PFOS) through electrostatic interactions. Regeneration of the fibers was enabled through a one-hour heat treatment at $550{ }^{\circ} \mathrm{C}$ in air. Overall, results from this study show that the nanoceria-immobilized silica nanofibers can be used as efficient oxidative and adsorptive media to treat TrOCs in acidic waters, without use of an additional catalyst separation stage from solution.
\end{abstract}

Received 8th May 2019

Accepted 11th June 2019

DOI: $10.1039 / c 9 r a 03467 f$

rsc.li/rsc-advances through a catalytic reaction with the dissolved $\mathrm{Fe}^{2+} / \mathrm{Fe}^{3+}$ redox pair. $^{5}$ However, homogeneous Fenton reactions suffer from fundamental drawbacks such as operation at low $\mathrm{pH}$ values (below 4), slow reduction kinetics, and significant accumulation of undesired iron sludge after neutralization.

In recent years, nanotechnology-based approaches have been increasingly explored to enhance or replace traditional decontamination methods. Through manipulation of material size, morphology, and chemical structure, nanomaterials can gain exceptional adsorptive and catalytic properties useful for water decontamination. ${ }^{6}$ Among nano-assisted AOPs, heterogeneous iron-free Fenton-like processes frequently rely on nanoscale transition metal oxide catalysts to facilitate effective contaminant degradation, many times overcoming the limitations of traditional Fenton processes. ${ }^{7}$

Cerium oxide $\left(\mathrm{CeO}_{2}\right.$ or ceria)-based materials are widely used in catalytic industrial applications, as well as in mechanical polishing, UV-shielding, and solid-oxide fuel cells. ${ }^{8}$ Specifically, catalytic redox reactions on the surface of ceria are mainly promoted by the formation of oxygen vacancy defects. ${ }^{9}$ The surface oxygen vacancy is generally accompanied by the reduction of $\mathrm{Ce}^{4+}$ ions to $\mathrm{Ce}^{3+}$ to balance the change in charge, resulting in both "oxygen buffering" behavior and potential catalytic reactivity of the ceria surface. ${ }^{10,11}$ Therefore, ceria nanoparticles (nanoceria) have gained considerable attention as a catalytic material due to their increase in effective surface concentration of surface $\mathrm{Ce}^{3+}$ species. ${ }^{12-14}$ 
Nanoceria is a versatile catalyst having both pro- and antioxidant actions. While the latter has been demonstrated as a strategy for scavenging reactive oxygen species (ROS) and eliminating oxidative stress in biological systems, ${ }^{15-18}$ nanoceria's intrinsic oxidation activity can be used to oxidize organics via the hydroxyl adduct route in environmental systems. ${ }^{19,20}$ Nanoceria usually exhibit strong oxidizing ability in the presence of an oxidizing agent (e.g. $\mathrm{H}_{2} \mathrm{O}_{2}$ ), but has also been reported to exhibit oxidative capabilities even in the absence of a strong oxidizing agent. ${ }^{17}$

Different approaches have been suggested to improve the catalytic activity of nanosized ceria, including changes in material design to enhance surface-to-volume ratio and increase the oxygen vacancy defect density, or by changes in operational design to maximize redox reactions. Material-based factors affecting nanoceria's redox reactions may include crystal structure, size distribution, and exposed facets. ${ }^{21}$ In liquid-phase applications, operational factors such as ion and redox agent presence, $\mathrm{pH}$, and oxygen level can affect nanoceria's reactivity, even leading to crystallite dissolution and reprecipitation. ${ }^{22}$

Changes in nanoceria's colloidal stability and potential effects on living cells ${ }^{23-25}$ are limiting factors in using nanoceria in water treatment applications such as adsorption, ${ }^{26}$ photocatalysis, ${ }^{27}$ and oxidation processes. ${ }^{20}$ Another limiting parameter in decontamination using suspended nanoparticles is the challenge of separating and recycling the nanoparticles after use. To address this limitation, ceria micro/nanocomposite structures-as opposed to nanoceria in suspension-have been suggested for facile separation and recycling after use. ${ }^{\mathbf{2 6 , 2 8}}$ For example, ceria flower-like particles and hollow fibers have been suggested as recoverable and regenerable structures for both antimicrobial and adsorptive purposes. ${ }^{26,28}$

In the context of nano-assisted water treatment technologies, electrospun nanofibers have attracted much attention as excellent nanomaterial carriers due to their high surface area, high porosity, and robust mechanical strength. ${ }^{29-31}$ Electrospun fibers can be tuned to achieve a desired chemical composition, structure, and stability, and can be post-treated to alter their chemical and structural properties. ${ }^{32}$ Affixing nanomaterials to the high surface area of electrospun fibers allows a high exposed surface area/mass ratio of the nanomaterial and, because the nanomaterial is irreversibly bound to the surface of the fibers, minimizes the risk of nanomaterial release to the environment. ${ }^{33}$ The exposed surface area/mass ratio of nanomaterial is especially important in decontamination because surface area, among other factors, can be related to functionalities like adsorption and oxidative capacity. ${ }^{34}$

In this study, we fabricated a reactive fibrous matrix by coating electrospun silica nanofibers with nanoceria for efficient water decontamination with easy reuse and regeneration properties. To optimize the oxidative operational conditions of ceria nanoparticles, they were analyzed both for their ability to oxidize of carbamazepine (CBZ) as a model TrOC as well as for their ability to generate $\mathrm{OH}$-radicals. These studies were conducted in the presence and absence of hydrogen peroxide, as well as across $\mathrm{pH}$ values. Using the resultant optimal operational conditions, the synthesized ceria nanofiber composites were used for oxidation and adsorption of a set of emerging TrOCs, such as CBZ, propranolol (PRO) and perfluorooctanesulfonic acid (PFOS). Finally, the facile reuse and regeneration properties of the ceria nanofiber composites were elucidated, rendering the electrospun ceria/silica nanofiber composites as a promising material for removal of a myriad of water contaminants of different chemical characteristics.

\section{Experimental}

\subsection{Fabrication of electrospun ceria/silica nanofiber composites}

Tetraethyl orthosilicate (TEOS, Sigma-Aldrich), phosphoric acid (85\%, Sigma-Aldrich), and deionized (DI) water (Milli-Q) were mixed together in the molar ratio of $1: 0.01: 11$, respectively, for $6 \mathrm{~h}$. An aqueous solution containing $10 \mathrm{wt} \%$ poly(vinyl alcohol) (PVA, $M_{\mathrm{w}}=89000-98000$, Sigma-Aldrich) was prepared by dissolving PVA powder in DI and mixing for 12 hours at $80^{\circ} \mathrm{C}$. Equal volumes of the TEOS gel and the PVA solution ( $5 \mathrm{~mL}$ of each) were mixed for 6 hours, and subsequently loaded in a $10 \mathrm{~mL}$ Luer-Lok Tip syringe (Becton Dickinson \& Co., Franklin Lakes, NJ) fitted with an $21 \mathrm{G} \times 1$ inch PrecisionGlide needle (Becton Dickinson \& Co.). After placing the syringe horizontally on the syringe pump (Harvard Apparatus, Plymouth Meeting, PA), an electrode of high-voltage supply (Gamma High Voltage Research Inc., Ormond Beach, FL) was connected to the syringe's needle tip. A grounded sheet of aluminum foil $(10.5 \mathrm{~cm} \times 38.5 \mathrm{~cm})$ was used as a nanofiber collector and installed on a rotating drum moving at approximately $16 \mathrm{~cm} \mathrm{~min}^{-1}$. The needle-to-collector distance, flow rate, and voltage were $11 \mathrm{~cm}, 0.5 \mathrm{~mL} \mathrm{~h}^{-1}$, and $13 \mathrm{kV}$, respectively. The electrospinning was performed in a closed chamber under controlled temperature $\left(30{ }^{\circ} \mathrm{C}\right)$ and relative humidity (30\%). Fibers were collected for 10 hours, removed from the collector, and subsequently calcined in a furnace (Thermolyne 48000 ) at $700{ }^{\circ} \mathrm{C}$ for 2 hours.

To immobilize $\mathrm{CeO}_{2}$ nanoparticles on the surface of the calcined silica fibers, $1 \mathrm{mg} \mathrm{mL}^{-1}$ suspension of cerium(Iv) oxide nanoparticles (30 nm particles in powder form, Sigma-Aldrich) at pH 2 (10 mM buffer acetate) was first sonicated in an ultrasonication bath (FS60, Fisher Scientific) for 15 min. Following sonication, $10 \mathrm{~mL}$ of the $\mathrm{CeO}_{2}$ nanoparticle suspension was poured over $10 \mathrm{mg}$ of silica fibers in a Petri dish and mixed overnight on an orbital shaker (KJ-201BD, Kangjian). After $\mathrm{CeO}_{2}$ immobilization, the ceria/silica nanofiber composites were washed three times with $10 \mathrm{~mL}$ of deionized water and dried at $60{ }^{\circ} \mathrm{C}$ overnight. The $\mathrm{CeO}_{2}$ mass immobilized on the fibers' surface was estimated by weighing the dry fiber mats before and after dip-coating in the $\mathrm{CeO}_{2}$ suspension. A schematic illustration of the electrospun ceria/silica nanofiber composites fabrication is provided in Fig. S.1 in ESI. $\dagger$

\subsection{Characterization of ceria nanoparticles and electrospun ceria/silica nanofiber composites}

Surface morphologies of commercial nanoceria and the nanofibers before and after modification with nanoceria were examined with a Hitachi scanning electron microscope (SEM) 
SU-70. Before SEM imaging, samples were dried at $60{ }^{\circ} \mathrm{C}$ overnight and then sputter-coated with an $8 \mathrm{~nm}$ coating of iridium (208HR, Cressington). Acceleration voltage of $5.0 \mathrm{kV}$ was applied during SEM analysis for all samples. The distribution of fiber diameters was determined from a random sampling of $\sim 30$ fibers from multiple SEM images of the same sample using ImageJ software (National Institutes of Health, Bethesda, MD).

The specific surface areas of nanoceria particles, electrospun silica nanofibers, and nanoceria-immobilized silica nanofibers were determined using a Micromeritics 3Flex static volumetric system with $\mathrm{Kr}$ as the analysis adsorptive. To assure moisturefree samples, samples were dried overnight and degassed under vacuum at $110{ }^{\circ} \mathrm{C}$ for at least 10 hours.

To determine both dispersed aggregate size and zeta potential of the nanoceria, suspensions of the nanoparticles $\left(0.5 \mu \mathrm{g} \mathrm{mL}^{-1}\right)$ were prepared in $10 \mathrm{mM}$ acetate buffer aqueous solution at $\mathrm{pH} 2$ and bath-sonicated for 10 minutes. To determine aggregate size, samples were immediately analyzed after sonication by dynamic light scattering (DLS, ALV-GmbH) using a multi-detector light scattering unit with a neodymium-doped vanadate laser (Verdi V2, Coherent, 78 Inc., Santa Clara, CA) operating at a wavelength of $532 \mathrm{~nm}$. DLS analysis was conducted at $90{ }^{\circ} \mathrm{C}$ for 12 runs, with 30 seconds of data collection for each run. To determine zeta potential, electrophoretic mobility measurements were taken using the NanoBrook Omni (Brookhaven Instruments, NY) with a $659 \mathrm{~nm}$ wavelength laser. The average and standard deviation of zeta potentials (using Smoluchowski approximation) were determined from 10 runs (30 cycles per run) for each sample.

The presence of nanoceria on the nanofiber composites was investigated by Fourier-transform infrared spectroscopy (FTIR) and Raman spectroscopy. FTIR spectra were recorded from 450 to $4000 \mathrm{~cm}^{-1}$ using a Thermo Nicolet 6700 spectrometer. Raman spectroscopy confirmed the binding of nanoceria to the fibers' surface, with spectra acquired using a $532 \mathrm{~nm}$ laser excitation on a Horiba Jobin Yvon HR-800 Raman spectrometer.

The hydrophilicity of the fibers was determined by the water contact angle using the sessile drop method and a goniometer (OneAttension, Biolin Scientific). A water droplet $(5 \mu \mathrm{L})$ was placed on the fibers and photographed using a digital camera for $15 \mathrm{~s}$. The left and right contact angles were analyzed from the digital images by post-processing software (OneAttension software) and averaged over six measurements (three contact angle measurements on two nanofiber samples).

Fiber porosity was estimated by gravimetric analysis. The oven-dried electrospun fibers were weighed and subsequently submerged in 2-propanol for one hour. After removal, the fibers were layered between nylon fabric (supplied by VWR), lightly pressed with Kimwipes for removal of excess 2-propanol and weighed. The porosity $(\varphi)$ was estimated using

$$
\varphi=\frac{V_{\text {pore }}}{V_{\text {total }}}=\frac{\frac{m_{\mathrm{IPA}}}{\rho_{\mathrm{IPA}}}}{V_{\text {pore }}+V_{\text {polymer }}}=\frac{\frac{m_{\mathrm{IPA}}}{\rho_{\mathrm{IPA}}}}{\frac{m_{\mathrm{IPA}}}{\rho_{\mathrm{IPA}}}+\frac{m_{\text {polymer }}}{\rho_{\text {polymer }}}}
$$

where $V, m$, and $\rho$ represent volume, mass, and density, respectively, IPA represents the 2-propanol, and polymer represents the electrospun mat. This procedure was performed three times, and the final porosity values were averaged.

The pore-size distribution was evaluated using the wet/dry flow method with a custom-made porometer setup. ${ }^{31}$ The electrospun fibers were cut by a $1 / 2$-inch diameter puncher and placed on a $13 \mathrm{~mm}$ stainless steel filter holder (Whatman, Maidstone, UK). Nitrogen gas pressure was controlled with a digital pressure regulator (Control Air Inc, Amherst, NH), gas flow across the membrane was monitored by a flow meter (Porter, Hatfield, PA), and pressure was monitored by a pressure transducer (Honeywell, Morris Plains, NJ).

\subsection{Optimization of nanoceria oxidative and adsorptive performance}

The oxidative and adsorptive performance of the nanoceria suspension toward carbamazepine (CBZ) and perfluorooctanesulfonic acid (PFOS) was tested in the presence of hydrogen peroxide $\left(\mathrm{H}_{2} \mathrm{O}_{2}\right.$, Sigma-Aldrich) at different concentrations (up to $10 \mathrm{mM}$ ) and across a $\mathrm{pH}$ range (2-6). The $\mathrm{pH}$ was adjusted using sodium hydroxide ( $\mathrm{NaOH}$ pellets, J. T. Baker) and hydrochloric acid ( $\mathrm{HCl}$, Sigma-Aldrich). In a typical experiment, environmentally-relevant concentrations of $1 \mathrm{mg} \mathrm{L^{-1 }}$ model contaminant (i.e., CBZ or PFOS) was mixed with $1 \mathrm{mg}$ $\mathrm{mL}^{-1} \mathrm{CeO}_{2}$ nanoparticles in $10 \mathrm{~mL}$ of buffer acetate solution (10 $\mathrm{mM}$ ) for one hour. Following this interaction, the mixed solution was centrifuged (13 $000 \mathrm{rpm}$ for 10 minutes) to remove ceria nanoparticles, and the supernatant was analyzed to quantify CBZ or PFOS removal as described in the analytical quantification of TrOCs subsection.

In a set of parallel oxidation experiments, OH-radical formation was quantified using a tertiary butanol assay. ${ }^{35}$ Tertiary butanol was added in excess $(100 \mathrm{mM})$ to a buffered $1 \mathrm{mg} \mathrm{mL}^{-1} \mathrm{CeO}_{2}$ nanoparticle suspension $(10 \mathrm{mM}$ acetate buffer) to readily react with $\mathrm{OH}$-radicals (rate constant of $6 \times$ $10^{8} \mathrm{M}^{-1} \mathrm{~s}^{-1}$ ). The main product formed by this reaction is formaldehyde, which was quantified by the Hantzsch method. ${ }^{36}$ A reagent solution ( $2 \mathrm{M}$ ammonium acetate, $0.05 \mathrm{M}$ of acetic acid, and $0.02 \mathrm{M}$ acetylacetone in water) was mixed with the tertiary butanol/ $\mathrm{CeO}_{2}$ supernatant with a $1: 1$ volume-tovolume ratio. The mixture was heated for 10 minutes at $50{ }^{\circ} \mathrm{C}$, and the change in color was measured spectrophotometrically at $412 \mathrm{~nm}$. Finally, OH-radical yield could be calculated using

$$
[\mathrm{OH}]=\frac{F_{\mathrm{e}}-F_{0}}{\varepsilon} D Y\left(\frac{\mathrm{OH}}{\mathrm{F}}\right)
$$

where $F_{\mathrm{e}}$ is the absorbance of the sample, $F_{0}$ is the absorbance of a blank (i.e., without $\mathrm{CeO}_{2}$ nanoparticles), $\varepsilon$ is the formaldehyde transformation product (diacetyldihydrolutidine) extinction coefficient $\left(8000 \mathrm{M}^{-1} \mathrm{~cm}^{-1}\right), D$ is the dilution factor with reagent (i.e., 2), and $Y\left(\frac{\mathrm{OH}}{\mathrm{F}}\right)$ is the correction factor of hydroxyl radical to formaldehyde yields $(\sim 2) .{ }^{35}$ This method is often used when fast competitive reactions with radicals are expected (e.g., during ozonation of wastewater), ${ }^{37}$ but can be used here to efficiently scavenge all $\mathrm{OH}$-radicals formed during interaction. 


\subsection{Oxidation experiments with electrospun $\mathrm{CeO}_{2}$ nanofiber composites}

The oxidative performance of the electrospun $\mathrm{CeO}_{2}$ nanofiber composites toward three TrOCs was tested at $\mathrm{pH} 2$ in the absence and presence $(0.5 \mathrm{mM})$ of hydrogen peroxide. The TrOCs-CBZ, propranolol (PRO), and perfluorooctanesulfonic acid (PFOS)-were chosen based on their environmental relevance and differing charge in acidic solution. Chemical structures and properties of the TrOCs are shown in Table A.1. $\dagger$ Oxidation experiments were performed in triplicate with $1 \mathrm{mg} \mathrm{L}^{-1} \mathrm{CBZ}$, PRO, or PFOS (separately) at $\mathrm{pH} 2$ in a buffered solution. $\mathrm{CeO}_{2}$ nanofiber composites were added to the solu-

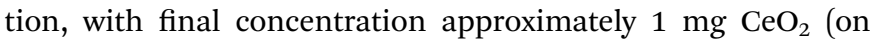
fibers) per $1 \mathrm{~mL}$ of TrOC solution. Samples were taken periodically, and the TrOC residual concentration was determined through HPLC (for CBZ and PRO) or HPLC-MS analysis (for PFOS). To quantify ceria release from the composite fibers during oxidation, cerium ion concentration in the final solution (following 2 hours of interaction) was measured by inductively coupled plasma mass spectrometry (ICP-MS, PerkinElmer, DRC-e) with a Meinhard nebulizer and argon plasma.

\subsection{Analytical quantification of TrOCs}

Concentrations of CBZ and PRO were determined using HPLC (Shimadzu LC-20AD) equipped with an Eclipse Plus C18 column $(1.8 \mu \mathrm{m}, 4.6 \times 50 \mathrm{~mm}$, Agilent) and a UV/Vis detector (SPD20AV). A sample volume of $100 \mu \mathrm{L}$ was injected using an isocratic mobile phase of solvent comprising $35 \%$ acetonitrile and $65 \%$ water with $0.1 \%(\mathrm{v} / \mathrm{v})$ phosphoric acid at a flow rate of 1.3 $\mathrm{mL} \min ^{-1}$. PFOS concentration was determined using HPLC (Agilent 1290 Infinity Series) coupled with a mass spectrometer (Agilent 6550A iFunnel Q-TOF MS). A sample volume of $1 \mu \mathrm{L}$ was injected into an Eclipse Plus C18 column using a mobile phase gradient of solvent comprised of $40 \%$ methanol and $60 \%$ water with $20 \mathrm{mM}$ ammonium acetate at a flow rate of $0.5 \mathrm{~mL} \mathrm{~min}^{-1}$. Methanol was increased from $40 \%$ to $98 \%$ in $5 \mathrm{~min}$, held for $1 \mathrm{~min}$, dropped back to $40 \%$, and stabilized for $1 \mathrm{~min}$. The QTOF MS was operated using an electrospray ionization (ESI) interface in negative mode.

\section{Results and discussion}

\subsection{Characteristics of ceria nanoparticles and electrospun ceria/silica nanofiber composites}

SEM micrographs (Fig. 1A, top) illustrate that commercial ceria nanoparticles aggregate into large aggregates. Changes in ceria nanoparticle aggregate size were also analyzed in aqueous solutions at pH 2 and 6 (Fig. S.2 in ESI $\dagger$ ). At pH 2, the ceria nanoparticles had a large zeta potential $(45.1 \mathrm{mV}$, Table 1$)$ and the aggregate size did not change over one hour $(43.0 \mathrm{~nm}$, Table 1), indicating colloidal stability at low solution $\mathrm{pH}$. However, at $\mathrm{pH} 6$, the ceria nanoparticles rapidly aggregated, which could be explained by reduced electrostatic repulsion between nanoparticles when solution $\mathrm{pH}$ is close to their point of zero-charge $(\sim 6.5) .^{38}$ As we discuss later, anchoring ceria nanoparticles to silica fiber mats could eliminate aggregation during water decontamination while enabling easy separation of the particles from treated solution. The specific surface area of ceria nanoparticles was $37.2 \pm 0.2 \mathrm{~m}^{2} \mathrm{~g}^{-1}$, similar to previous measurements reported in literature. ${ }^{9}$

Silica nanofibers were chosen as the substrate material for catalytic nanoceria because of their thermal stability (allowing facile thermal regeneration), negative surface charge ${ }^{39}$ (attracting positively charged nanoceria), and outstanding mechanical properties. Representative characteristics of silica fiber mats are outlined in Table 1. SEM micrographs (Fig. 1A, center) illustrate the cylindrical structure of electrospun glass fibers which were devoid of beads or branched structures. The fiber diameters follow a typical Gaussian distribution (Fig. 1B) with an average fiber diameter of $176.6 \mathrm{~nm}$. The silica nanofiber mats are porous (Fig. S.3 in ESI $\dagger$ ) and hydrophilic with a contact angle of $<10^{\circ}$ (Table 1), consistent with previous studies on electrospun silica fibers. ${ }^{40}$

Surface modification of the silica nanofibers with ceria nanoparticles was characterized through SEM, Raman spectroscopy, and FTIR. SEM micrographs for electrospun silica nanofibers (Fig. 1A, center) and ceria/silica nanofiber composites (Fig. 1A, bottom) illustrate nanoceria bound to the surface of the silica fiber mats. Using ImageJ image processing software, an average nanoceria aggregate size of $52 \pm 21 \mathrm{~nm}$ was determined using at least 100 ceria nanoparticles from three representative SEM images. Using a mass balance of six sets of dry fiber mats, the typical loading was $18.0 \pm 3.7 \mathrm{mg} \mathrm{CeO}$ per $35.0 \pm 1.2 \mathrm{mg}$ of fibers. No significant change was seen in the nanocomposite specific surface area $\left(27.2 \pm 0.1 \mathrm{~m}^{2} \mathrm{~g}^{-1}\right)$ as compared to that of pristine silica nanofibers $\left(27.1 \pm 0.2 \mathrm{~m}^{2}\right.$ $\mathrm{g}^{-1}$ ). This minimal change in surface area after surface functionalization with ceria nanoparticles is mainly due to the moderate ceria loading ( $\sim 34 \%$ by weight), and because ceria clusters (rather than nanoparticles) are bound to the surface of the fibers.

The functionalization of the silica fibers with ceria nanoparticles was also confirmed by Raman spectroscopy (Fig. 1C). For the pristine electrospun silica mats, no prominent bands between $200-3500 \mathrm{~cm}^{-1}$ were observed. However, upon modification with nanoceria, a sharp single peak at $\sim 465 \mathrm{~cm}^{-1}$ appeared, representing the optical Raman $\mathrm{F}_{2 \mathrm{~g}}$ mode attributed to the symmetric breathing of oxygen atoms in the $\mathrm{CeO}_{2}$ lattice. ${ }^{41}$

FTIR was used to demonstrate the bonding of ceria to the active functional groups $\left(\mathrm{Si}-\mathrm{OH}\right.$ and $\mathrm{Si}^{-} \mathrm{O}^{-}$) on the silica nanofibers, both before and after ceria deposition (Fig. 1D). The peaks at $1100 \mathrm{~cm}^{-1}$ and $1090 \mathrm{~cm}^{-1}$ in the silica fiber sample illustrate asymmetric stretching and deformation of $\mathrm{Si}-\mathrm{O}$ and $\mathrm{Si}-\mathrm{O}-\mathrm{Si}$ bonds, respectively, ${ }^{42,43}$ while the peak at $950 \mathrm{~cm}^{-1}$ indicates the stretching of $\mathrm{Si}-\mathrm{OH}$ bonds and $\mathrm{SiO}^{-}$groups. The peaks at $810 \mathrm{~cm}^{-1}$ and $470 \mathrm{~cm}^{-1}$ are related to the symmetrical stretching and in-plane bending of the $\mathrm{Si}-\mathrm{O}-\mathrm{Si}$ modes, respectively. After addition of $\mathrm{CeO}_{2}$ to the fibers, the $\mathrm{Ce}-\mathrm{O}$ and $\mathrm{Ce}-\mathrm{Si}$ peaks become distinguishable in the range between 400 and $450 \mathrm{~cm}^{-1} .^{44,45}$ Corroborating this evidence of ceria on the surface of the fibers is the decrease in the peak at $950 \mathrm{~cm}^{-1}$, which arises from dangling oxygen atoms, as well as a shift in 
A

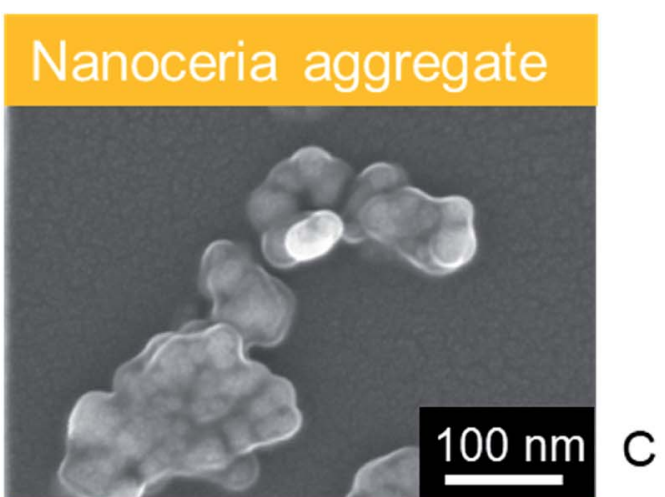

B
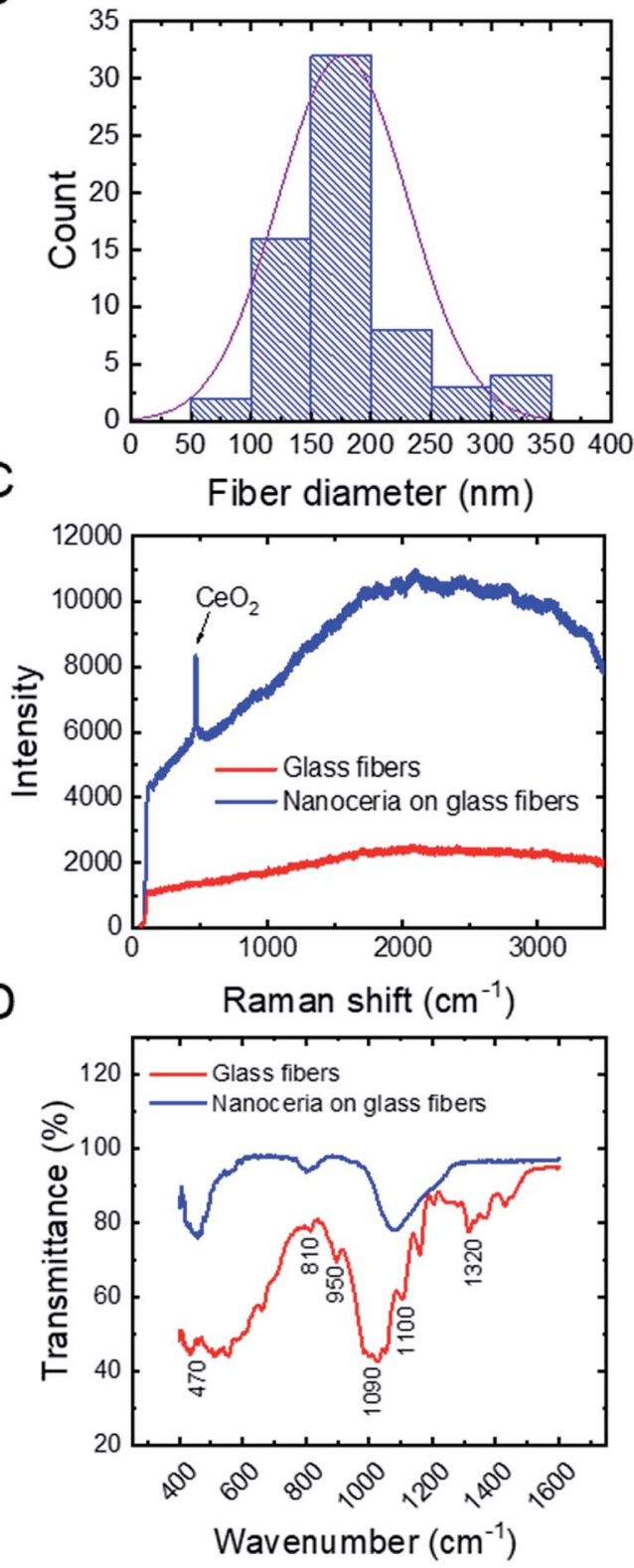

Fig. 1 Characteristics of electrospun ceria/silica nanofiber composites. (A) SEM images of ceria aggregate (top), pristine fibers (center), and $\mathrm{CeO}_{2}$-immobilized fibers (bottom). Inset scale bar is $100 \mathrm{~nm}$. (B) Diameter distribution of ceria/silica nanofiber composites. (C) Raman and (D) FTIR spectra of pristine fibers (red) and ceria/silica nanofiber composites (blue), indicating the presence of ceria nanoparticles on the surface of the nanofibers.

the $\mathrm{Si}-\mathrm{O}-\mathrm{Si}$ asymmetrical stretching at $1100 \mathrm{~cm}^{-1}$; both changes are associated with electropositive cerium ions bound to electronegative oxygen in the silica nanofibers. ${ }^{46}$

\subsection{Optimization of operational conditions for TrOC removal by ceria nanoparticles}

To optimize the oxidative and adsorptive conditions for TrOC removal, pristine $\mathrm{CeO}_{2}$ nanoparticles were tested for removal of a model compound, carbamazepine (CBZ), across pH values (26) and $\mathrm{H}_{2} \mathrm{O}_{2}$ concentrations (up $10 \mathrm{mM}$ ). As shown in Fig. 2 (blue open circles), higher CBZ removal was associated with higher $\mathrm{OH}$-radical formation, suggesting that $\mathrm{CBZ}$ was oxidized by the formed radicals rather than adsorbed to the ceria nanoparticles. Appearance of secondary peaks in HPLC chromatographs strengthen this claim, as they indicate possible formation of CBZ transformation products during oxidation by the ceria nanoparticles (Fig. S.4 in ESI $\dagger$ ).

Decreasing solution $\mathrm{pH}$ resulted in higher removal efficiency of $\mathrm{CBZ}$ as well as higher OH-radical formation (Fig. 2A), suggesting that ceria nanoparticles act as an oxidizing heterogeneous catalyst in acidic conditions. When $\mathrm{H}_{2} \mathrm{O}_{2}$ was added to a pristine $\mathrm{CeO}_{2}$ nanoparticle suspension, the color of the 
Table 1 Key properties for ceria nanoparticles and glass fibers. Ceria nanoparticle aggregate size and zeta potential were measured using a 0.5 $\mu \mathrm{g} \mathrm{m}^{-1}$ nanoparticle suspension in $10 \mathrm{mM}$ acetate buffer aqueous solution at $\mathrm{pH} 2$

Ceria nanoparticles

Glass fibers

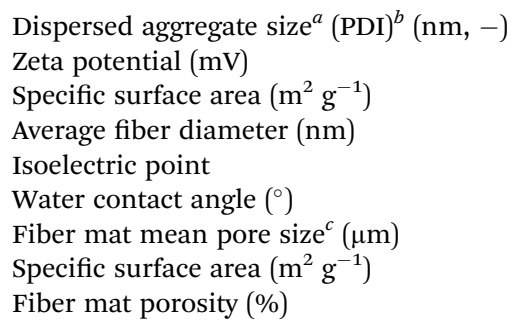
$43.0(0.24)$
$45.1 \pm 0.5$
$37.2 \pm 0.2$
176.6
$\sim 2$ (ref. 39)
$<10$
1.59
$27.1 \pm 0.2$
$96.5 \pm 0.4$

${ }^{a}$ Determined by dynamic light scattering (averaged over one hour of data collection). ${ }^{b}$ Polydispersity index. ${ }^{c}$ Based on pore-size distribution (Fig. A.3B in ESI).

suspension promptly changed from nearly colorless to yellow, providing a visible indication of formation of surface peroxide complex. ${ }^{47}$ A hydrogen peroxide concentration of $0.5 \mathrm{mM}$ maximizes both removal efficiency of $\mathrm{CBZ}$ and $\mathrm{OH}$-radical formation (Fig. 2B), indicating that ceria nanoparticles catalyze a Fenton-like reaction with hydrogen peroxide. ${ }^{11}$ Higher concentrations of hydrogen peroxide did not produce a significantly higher concentration of $\mathrm{OH}$-radicals or increase $\mathrm{CBZ}$ removal efficacy.

Control kinetic experiments suggest that exposure to either $\mathrm{H}_{2} \mathrm{O}_{2}$ (i.e., without ceria addition) or ceria nanoparticles (i.e., without $\mathrm{H}_{2} \mathrm{O}_{2}$ addition) is not sufficient to induce $\mathrm{CBZ}$ removal (Fig. 2C). These results are similar to those of Abdelkader et al., who found a synergistic relationship between a cerium oxide polishing powder and $\mathrm{H}_{2} \mathrm{O}_{2}$ in the oxidation of neutral red dye. ${ }^{48}$ In their study, a homogeneous $\mathrm{H}_{2} \mathrm{O}_{2}$ system achieved $12.58 \%$ oxidation of the dye and the cerium oxide powder achieved $67.36 \%$ oxidation, each after 60 minutes. However, a heterogeneous system of both the cerium oxide powder and $\mathrm{H}_{2} \mathrm{O}_{2}$ achieved $85.9 \%$ oxidation after 60 minutes, illustrating a synergetic effect from increased $\mathrm{OH}$-radical production. Similarly, our control experiments at low solution $\mathrm{pH}$ (2) show negligible CBZ oxidation by $\mathrm{H}_{2} \mathrm{O}_{2}$ and ceria nanoparticles $(3-4 \%$ in both experiments, Fig. 2C) after 60 minutes, while heterogeneous system of both the ceria nanoparticles and $\mathrm{H}_{2} \mathrm{O}_{2}$ achieved over
$99 \%$ oxidation after 60 minutes. The reaction rate for oxidation of $1 \mathrm{mg} \mathrm{L}^{-1} \mathrm{CBZ}\left(0.08 \mathrm{~min}^{-1}\right)$ is similar to that achieved by homogenous Fenton $\left(\sim 0.1 \mathrm{~min}^{-1}\right){ }^{49}$

Cerium has been illustrated as a redox-cycling metal capable of generating highly-reactive radicals in the presence of peroxide. ${ }^{50}$ This catalytic behavior was directly related to the ceria's ability to cycle between the $3+$ and $4+$ states at oxygen vacancy sites. However, as $\mathrm{Ce}^{3+}$ is an intermediate valence state of ceria that could be rapidly oxidized to $\mathrm{Ce}^{4+}$ in the presence of the $\mathrm{H}_{2} \mathrm{O}_{2},{ }^{9,51}$ we could only observe the $4+$ state on the surface of ceria nanoparticles by XPS analysis prior to and following addition of $0.5 \mathrm{mM} \mathrm{H}_{2} \mathrm{O}_{2}$ (Fig. S.5 in ESI†े). Interestingly, ceriabased materials have also shown promise as antioxidants and radical scavengers in both cell culture models and animal studies. $^{15-17,52}$ These seemingly contradictory phenomena are likely due to differences in media (i.e., biological and environmental media) and applied dosages of ceria.

In addition to their oxidative performance, positivelycharged $\mathrm{CeO}_{2}$ nanoparticles have the potential to adsorb negatively-charged persistent TrOCs through electrostatic attractions, as demonstrated in experimentation with perfluorooctanesulfonic acid (PFOS) as a representative compound (Fig. 3). Adsorption of PFOS was evaluated at several $\mathrm{pH}$ values and $\mathrm{H}_{2} \mathrm{O}_{2}$ concentrations. Not surprisingly, adsorption of PFOS was significantly higher at low solution $\mathrm{pH}$, far from the $\mathrm{CeO}_{2}$
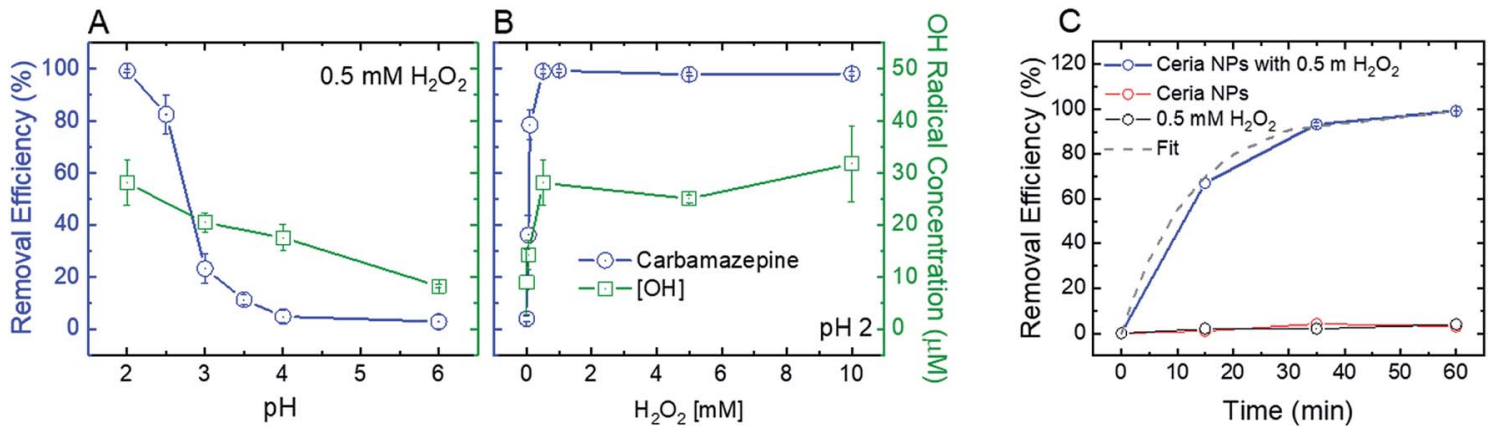

Fig. 2 Effect of (A) $\mathrm{pH}$ and (B) $\mathrm{H}_{2} \mathrm{O}_{2}$ concentration on the removal efficiency of $1 \mathrm{mg} \mathrm{L}^{-1}$ carbamazepine (blue) and $\mathrm{OH}$-radical formation (green) by $1 \mathrm{mg} \mathrm{mL}^{-1} \mathrm{CeO}_{2}$ nanoparticles in $10 \mathrm{mM}$ buffer acetate solution after 1 hour of mixing. Experiments were carried out under ideal conditions for maximum removal efficiency and $\mathrm{OH}$ radical generation: $\mathrm{pH}_{2}$ and $0.5 \mathrm{mM} \mathrm{H}_{2} \mathrm{O}_{2}$. (C) Removal kinetics of $1 \mathrm{mg} \mathrm{L}^{-1}$ carbamazepine by $1 \mathrm{mg} \mathrm{L}^{-1}$ ceria nanoparticles (NPs) at pH 2 in the presence of $0.5 \mathrm{mM} \mathrm{H}_{2} \mathrm{O}_{2}$ (blue line) and best-fit line (pseudo-first order, dashed grey line). Isolated effect of $\mathrm{H}_{2} \mathrm{O}_{2}$ (black line) without ceria NP addition and ceria NPs in the absence of $\mathrm{H}_{2} \mathrm{O}_{2}$ (red line) on carbamazepine removal was determined as well. 
point of zero-charge $(\sim 6.5) \cdot{ }^{38}$ Due to the very low $\mathrm{p} K_{\mathrm{a}}$ value of PFOS (-3.27), electrostatic attraction is likely to be responsible for its adsorption even at low $\mathrm{pH}^{53,54}$

Addition of hydrogen peroxide to the $\mathrm{CeO}_{2}$ adsorption matrix decreased the removal of PFOS at all pH values tested (Fig. 3A). This decrease in PFOS adsorption upon addition of hydrogen peroxide is possibly due to competition over reactive sites on the ceria nanoparticle surface. The kinetics of sorption (Fig. 3B) illustrate a rapid and significant decrease in PFOS concentration in the supernatant (i.e., following separation from nanoparticles) after ten minutes of adsorption, which resulted in $98 \%$ removal of PFOS by the ceria nanoparticles.

\subsection{Oxidation and adsorption of TrOCs by electrospun ceria/silica nanofiber composites}

Optimal batch conditions of $\mathrm{pH} 2$ and $0.5 \mathrm{mM} \mathrm{H}_{2} \mathrm{O}_{2}$ were used to establish removal kinetics of PRO, CBZ, and PFOS using the electrospun ceria/silica nanofiber composites (Fig. 4). In the absence of hydrogen peroxide, no PRO and CBZ were removed, suggesting that the nanofiber composites had negligible adsorptive capacity toward these TrOCs. However, addition of $0.5 \mathrm{mM} \mathrm{H}_{2} \mathrm{O}_{2}$ resulted in almost-complete oxidation of the positively- and neutrally-charged TrOCs (95 and 98\%, respectively) following two hours of interaction with similar pseudofirst order kinetics $\left(0.03 \mathrm{~min}^{-1}\right)$. Control experiments showed that pristine nanofibers had minor effect on PRO and CBZ removal (Fig. S. 6 in ESI $\dagger$ ) under optimal oxidation conditions (i.e., $\mathrm{pH} 2$ and $0.5 \mathrm{mM} \mathrm{H}_{2} \mathrm{O}_{2}$ ), indicating oxidation by the immobilized ceria as the sole removal mechanism. The removal kinetics by the nanofiber composite (i.e., when ceria was immobilized on the composite) was significantly lower than that of the nanoparticles alone (Fig. 2C) due to a decrease in both available reactive nanoparticle surface area and probability of interaction with pollutants.

We note that even when ceria nanoparticle aggregation was prevented through immobilization onto the silica nanofibers, experiments at higher $\mathrm{pH}($ e.g., $\mathrm{pH}$ 6) in the presence of hydrogen peroxide showed negligible removal of both PRO and

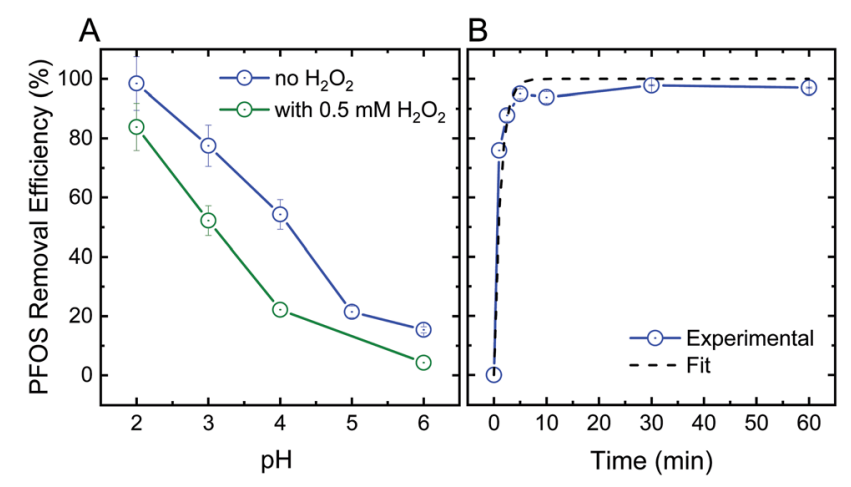

Fig. 3 (A) Effect of $\mathrm{pH}$ on the adsorption efficiency of $1 \mathrm{mg} \mathrm{L}^{-1}$ perfluorooctanesulfonic acid (PFOS) by $1 \mathrm{mg} \mathrm{mL}^{-1}$ ceria nanoparticles after 1 hour of mixing in the absence (blue) and presence (green) of $0.5 \mathrm{mM} \mathrm{H}_{2} \mathrm{O}_{2}$. (B) PFOS adsorption kinetics and best-fit line (pseudofirst order) at $\mathrm{pH} 2$.
CBZ by the ceria/silica nanofibers (Fig. S.6 in ESI $\dagger$ ). This limited oxidation performance at higher solution $\mathrm{pH}$ is indicative of the inherent catalytic characteristics of nanoceria, which rely on the existence of oxygen vacancies on the surface of ceria nanoparticles to allow for redox mechanisms in catalysis as well as activation by oxygen containing compounds $\left(e . g ., \mathrm{H}_{2} \mathrm{O}_{2}\right){ }^{19,20}$

Removal of PFOS reached $69 \%$ after two hours of interaction with the ceria/silica nanofiber composite (Fig. 4C). Control experiments showed that pristine nanofibers adsorb approximately $19 \%$ of the PFOS after 2 hours, illustrating that ceria does not account for all adsorption achieved by the nanocomposite. Because the fibers adsorb PFOS, it can be inferred that the ceria nanoparticles on the fibers are responsible for less than $69 \%$ removal of PFOS (the total amount removed by the nanocomposite), which is a significant decrease in PFOS adsorption achieved by the same loading of ceria nanoparticles in suspension (98\%, Fig. 3B).

This decrease in adsorption performance of the ceria/fiber nanofiber composite as compared to the rapid and full PFOS adsorption with suspended nanoceria (Fig. 3B) could possibly be explained by limitations in both ceria surface area and contaminant diffusion toward ceria's adsorptive sites. Ceria nanoparticles alone have a surface area of $37.2 \pm 0.2 \mathrm{~m}^{2} \mathrm{~g}^{-1}$, but when added to the surface of the fibers, they impart a negligible change in the nanocomposite surface are (which, as mentioned previously, increases from $27.1 \pm 0.2 \mathrm{~m}^{2} \mathrm{~g}^{-1}$ to $27.2 \pm 0.1 \mathrm{~m}^{2}$ $\mathrm{g}^{-1}$ after ceria immobilization). In addition, by anchoring ceria on the fibers, ceria's contact with contaminants is limited because the ceria nanoparticles now cannot move freely in suspension, limiting their number of interactions with contaminants of concern.

Our results collectively suggest that although immobilized ceria nanoparticles can serve as an efficient oxidative media in acidic conditions, they have limited adsorption performance. For practical application, ceria nanoparticles could be coupled with a conventional adsorbent (e.g., activated carbon), strategically imparting oxidative capabilities on materials typically known for their singular adsorptive capability.

Both oxidative and adsorptive performances of the electrospun ceria/silica nanofiber composites are maximized in acidic conditions, limiting the applicability for water decontamination. However, such a system should be considered not only when $\mathrm{pH}$ can be adjusted for optimal treatment, but also for niche applications, such as treatment of contaminated acidic waters. For example, wastewaters that may benefit from decontamination at low $\mathrm{pH}$ are acid mine drainage (with mostly inorganic contamination and some secondary organic pollution $)^{55,56}$ as well as some industrial wastes such as metal plating $^{57}$ and dairy wastes ${ }^{58}$ laden with veterinary antibiotics ${ }^{59,60}$ and detergents. ${ }^{61}$ To increase the feasibility and potential of these fibers in treating a variety of contaminants (as opposed to only organic contaminants, as studied herein), future studies are recommended in the use and regeneration of these fibers in the context of inorganic pollutant removal. The concentration of $\mathrm{H}_{2} \mathrm{O}_{2}$ (i.e., $0.5 \mathrm{mM}$ ) needed to oxidize pollutants (at a concentration of $\sim 5 \mu \mathrm{M}$ ) is within the lower range of concentrations used for a typical $\mathrm{H}_{2} \mathrm{O}_{2} / \mathrm{UV}$ advanced oxidation 


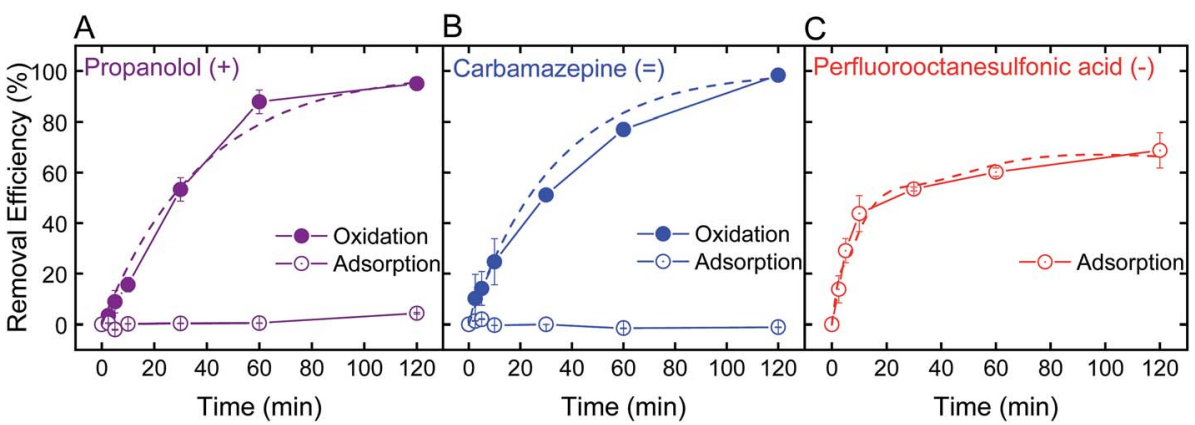

Fig. 4 Removal kinetics and best-fit line (pseudo-first order) of $1 \mathrm{mg} \mathrm{L}^{-1}$ (A) propranolol (purple), (B) carbamazepine (blue), and (C) perfluorooctanesulfonic acid (red) by electrospun ceria/silica nanofiber composites for a final concentration of $1 \mathrm{mg}$ nanoceria per mL of treated solution, through oxidation (solid circles) at pH 2 in $0.5 \mathrm{mM} \mathrm{H}_{2} \mathrm{O}_{2}$ and adsorption (open circles) at pH 2 and no $\mathrm{H}_{2} \mathrm{O}_{2}$.

process, which is dictated by the low molar absorption coefficient of $\mathrm{H}_{2} \mathrm{O}_{2}$ as well as the need to overcome scavenging effects by constituents in the treated waters. ${ }^{62}$

\subsection{Reuse and regeneration of electrospun ceria/silica nanofiber composites}

Using CBZ as a model TrOC, experiments were conducted to determine the oxidative performance of the composite fibers after multiple oxidation cycles and regeneration. The ceria/ silica nanofiber composites could be reused for oxidation many times, with only an approximate 15\% drop in oxidative performance after 10 cycles (Fig. 5A). The fibers were then regenerated by facile heating at $550{ }^{\circ} \mathrm{C}$ in air for one hour. After regeneration, the fibers regained their initial oxidative performance (99\% recovery). This performance is quite impressive, as multiple oxidation cycles cause very little drop in performance (allowing much more treatment of water before eventual regeneration) and the fibers immediately return to their initial performance after regeneration. Because of the high energy requirements for heating the fibers to $550{ }^{\circ} \mathrm{C}$, other regeneration options should be considered, such as $\mathrm{pH}$ change, as has been illustrated by desorption of cationic organics from negatively-charged silicate surfaces. ${ }^{63}$

Using PFOS as a model TrOC, experiments were also conducted to determine the reuse of the composite fibers over multiple cycles of adsorption as well as after regeneration. As opposed to the multiple cycles of oxidative use before necessary regeneration, only three cycles of adsorption were possible before regeneration was necessary (Fig. 5B). This difference in time required before regeneration is due to the consumption of adsorption sites on ceria nanoparticles. When oxidation is the predominant mechanism of removal, as opposed to adsorption, the reactive sites continue to remain effective after use. However, when a contaminant sorbs to an adsorption site, that sorption site cannot be used in future adsorption. This explains the decrease in adsorption by approximately 50\% after each subsequent cycle. Regeneration of the fibers after adsorption, however, can be accomplished similarly to regeneration after oxidation (i.e., heating to $500{ }^{\circ} \mathrm{C}$ in air for one hour).

Leaching of cerium ions from the fibers was also evaluated over the course of multiple oxidative cycles of reuse. The first cycle of oxidation incurred a leaching of $800 \mu \mathrm{g} \mathrm{L}^{-1}$, which was approximately $5 \%$ of the total ceria on the surface of the
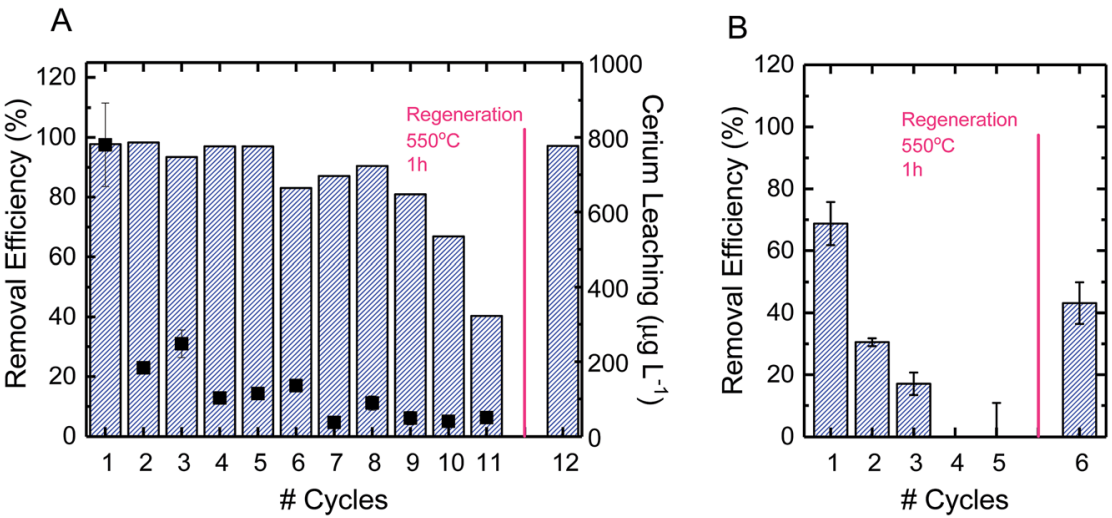

Fig. 5 (A) Reuse cycles of electrospun ceria/silica nanofiber composites for carbamazepine oxidation in the presence of $0.5 \mathrm{mM} \mathrm{H} \mathrm{H}_{2} \mathrm{O}_{2}$ (bars). The right axis shows leaching of cerium from the nanofiber composites to the solution (solid squares). (B) Reuse cycles of nanofiber composites for perfluorooctanesulfonic acid adsorption in the absence of $\mathrm{H}_{2} \mathrm{O}_{2}$ (bars). In each cycle, $1 \mathrm{mg} \mathrm{L}^{-1}$ pollutant solution at $\mathrm{pH} 2$ (10 $\mathrm{mM}$ buffer acetate) was added to nanofiber composites for a final concentration of $1 \mathrm{mg}$ nanoceria per $\mathrm{mL}$ of treated solution for 2 hours of mixing. The figure also shows nanofiber composite recovery following a thermal regeneration at $550^{\circ} \mathrm{C}$ in air for one hour. 
composite fibers (Fig. 5A). There are currently no federal standards for cerium leaching, ${ }^{\mathbf{6 4 , 6 5}}$ so further studies are recommended to elucidate the effect of this level of leaching. After repeated cycles, however, the leaching per cycle decreased to less than $1 \%$. In practice, a possible way to avoid the higher ceria leaching of the first cycle is to soak the fresh composite fibers in DI water before beginning oxidative cycles.

\section{Conclusions}

This study proposes the design of regenerable nanoceria/silica nanofibers for decontamination of water through both Fentonlike oxidation reactions and adsorption. In ideal batch conditions (determined using ceria nanoparticles alone), the nanocomposite fibers achieve 95\% and 98\% oxidation of positivelyand neutrally-charged model trace organic compounds, respectively. Over the course of 10 oxidation cycles using the nanoceria/ silica nanofibers, performance drops by less than $15 \%$, and after heating, is brought back to the levels of initial performance. Using a different mechanism, i.e. through adsorption, these fibers also achieve more than $65 \%$ removal of a negatively-charged model trace organic compound (perfluorooctanesulfonic acid) through electrostatic attraction. After multiple adsorptive cycles, the same regenerative process as with oxidation can be used to reclaim the fibers for additional adsorption cycles. These fibers therefore prove themselves as multifunctional, regenerable nanocomposites, able to both oxidize and/or adsorb multiple trace organic compounds of concern.

\section{Conflicts of interest}

There are no conflicts to declare.

\section{Acknowledgements}

We acknowledge the National Science Foundation (NSF) Nanosystems Engineering Research Center for Nanotechnology-Enabled Water Treatment (Grant EEC1449500). Facility use was supported by Facility for Light Scattering, YINQE, and West Campus Analytical Core. The authors would like to thank Dr Chiheng Chu, Prof. Jea-Hong Kim, and Dr Igal Gozlan for their support with HPLC analysis and Dr Amanda Lounsbury and Danielle Lee for their advice and help with data analysis. BET measurements were conducted the Particle Testing Authority in Munich by Dr Torben Sick as well as Adi Ben-Yaakov and Omer Shenkman, both representatives of Dr Golik Scientific Solutions. We also acknowledge the YIBS Postdoctoral Fellowship and Tel Aviv University Presidential Postdoctoral Fellowship awarded to I. Z. and the Scientific and Technological Research Council of Turkey (TUBITAK) Department of Science Fellowships and Grant Programs (1059B191501137) for financially supporting N. D.

\section{Notes and references}

1 M. A. Shannon, P. W. Bohn, M. Elimelech, J. G. Georgiadis, B. J. Mariñas and A. M. Mayes, Nature, 2008, 452, 301-310.
2 Y. Luo, W. Guo, H. H. Ngo, L. D. Nghiem, F. I. Hai, J. Zhang, S. Liang and X. C. Wang, Sci. Total Environ., 2014, 473-474, 619-641.

3 USEPA, Integrated Risk Information System (IRIS), online database, 2014.

4 M. M. Huber, S. Canonica, G. Y. Park and U. von Gunten, Environ. Sci. Technol., 2003, 37, 1016-1024.

5 A. Babuponnusami and K. Muthukumar, J. Environ. Chem. Eng., 2014, 2, 557-572.

6 M. S. Mauter, I. Zucker, F. Perreault, J. R. Werber, J. Kim and M. Elimelech, Nat. Sustain., 2018, 1, 166-175.

7 M. Aleksić, H. Kušić, N. Koprivanac, D. Leszczynska and A. L. Božić, Desalination, 2010, 257, 22-29.

8 P. Ni, X. Wei, J. Guo, X. Ye and S. Yang, RSC Adv., 2015, 5, 97512-97519.

9 E. Mamontov, T. Egami, R. Brezny, M. Koranne and S. Tyagi, J. Phys. Chem. B, 2000, 104, 11110-11116.

10 S. Deshpande, S. Patil, S. V. Kuchibhatla and S. Seal, Appl. Phys. Lett., 2005, 87, 1-3.

11 Y. Zhou, Nanostructured cerium oxide based catalysts: synthesis, physical properties, and catalytic performance, PhD thesis, University of Nebraska, 2015.

12 E. Grulke, K. Reed, M. Beck, X. Huang, A. Cormack and S. Seal, Environ. Sci.: Nano, 2014, 1, 429-444.

13 K. Reed, A. Cormack, A. Kulkarni, M. Mayton, D. Sayle, F. Klaessig and B. Stadler, Environ. Sci.: Nano, 2014, 1, 390405.

14 A. Kumar, S. Das, P. Munusamy, W. Self, D. R. Baer, D. C. Sayle and S. Seal, Environ. Sci.: Nano, 2014, 1, 516-532.

15 S. S. Lee, W. Song, M. Cho, H. L. Puppala, P. Nguyen, H. Zhu, L. Segatori and V. L. Colvin, ACS Nano, 2013, 7, 9693-9703.

16 B. Nelson, M. Johnson, M. Walker, K. Riley and C. Sims, Antioxidants, 2016, 5, 15.

17 J. M. Perez, A. Asati, S. Nath and C. Kaittanis, Small, 2008, 4, 552-556.

18 C. Xu and X. Qu, NPG Asia Mater., 2014, 6, 1-16.

19 F. Chen, X. Shen, Y. Wang and J. Zhang, Appl. Catal., B, 2012, 121-122, 223-229.

20 M. A. Asati, D. S. Santra, M. C. Kaittanis, D. S. Nath and P. J. M. Perez, Angew. Chem., 2009, 48, 2308-2312.

21 M. Taguchi, S. Takami, T. Naka and T. Adschiri, Cryst. Growth Des., 2009, 9, 5297-5303.

22 P. Yu, S. A. Hayes, T. J. O'Keefe, M. J. O'Keefe and J. O. Stoffer, J. Electrochem. Soc., 2006, 153, C74-C79.

23 F. Rollin-Genetet, C. Seidel, E. Artells, M. Auffan, A. Thiéry and C. Vidaud, Chem. Res. Toxicol., 2015, 28, 2304-2312.

24 V. Shah, S. Shah, H. Shah, F. J. Rispoli, K. T. McDonnell, S. Workeneh, A. Karakoti, A. Kumar and S. Seal, PLoS One, 2012, 7, e47827.

25 A. Asati, S. Santra, C. Kaittanis and J. M. Perez, ACS Nano, 2010, 4, 5321-5331.

26 L. S. Zhong, J. S. Hu, A. M. Cao, Q. Liu, W. G. Song and L. J. Wan, Chem. Mater., 2007, 19, 1648-1655.

27 J. M. Coronado, A. Javier Maira, A. Martínez-Arias, J. C. Conesa and J. Soria, J. Photochem. Photobiol., A, 2002, 150, 213-221. 
28 Q. Cui, X. Dong, J. Wang and M. Li, J. Rare Earths, 2008, 26, 664-669.

29 S. Homaeigohar and M. Elbahri, Materials, 2014, 7, 10171045.

30 Z. M. Huang, Y. Z. Zhang, M. Kotaki and S. Ramakrishna, Compos. Sci. Technol., 2003, 63, 2223-2253.

31 E. Shaulsky, S. Nejati, C. Boo, F. Perreault, C. O. Osuji and M. Elimelech, J. Membr. Sci., 2017, 530, 158-165.

32 G. Andreas and W. H. Joachim, Angew. Chem., 2007, 46, 5670-5703.

33 A. F. de Faria, F. Perreault, E. Shaulsky, L. H. Arias Chavez and M. Elimelech, ACS Appl. Mater. Interfaces, 2015, 7, 12751-12759.

34 L. Zhi, W. Zuo, F. Chen and B. Wang, ACS Sustainable Chem. Eng., 2016, 4, 3398-3408.

35 R. Flyunt, A. Leitzke, G. Mark, E. Mvula, E. Reisz, R. Schick and C. von Sonntag, J. Phys. Chem. B, 2003, 107, 7242-7253.

36 T. Nash, Biochem. J., 1953, 55, 416-421.

37 T. Nöthe, H. Fahlenkamp and C. von Sonntag, Environ. Sci. Technol., 2009, 43, 5990-5995.

38 K. M. Buettner, C. I. Rinciog and S. E. Mylon, Colloids Surf., A, 2010, 366, 74-79.

39 G. V. Franks, J. Colloid Interface Sci., 2002, 249, 44-51.

40 Z. V. Feng, W. S. Chen, K. Keratithamkul, M. Stoick, B. Kapala, E. Johnson, A. C. Huang, T. Y. Chin, Y. W. Chen-Yang and M. L. Yang, Int. J. Nanomed., 2016, 11, 729-741.

41 D. Mukherjee, B. G. Rao and B. M. Reddy, Top. Catal., 2017, 60, 1673-1681.

42 M. C. Matos, L. M. Ilharco and R. M. Almeida, J. Non-Cryst. Solids, 1992, 147-148, 232-237.

43 K. M. S. Khalil, H. A. Mahmoud and T. T. Ali, Langmuir, 2008, 24, 1037-1043.

44 A. Singh and C. A. Hogarth, J. Mater. Sci., 1988, 23, 10901097.

45 C. Ho, J. C. Yu, T. Kwong, A. C. Mak and S. Lai, Chem. Mater., 2005, 4514-4522.

46 P. Munusamy, S. Sanghavi, T. Varga and T. Suntharampillai, RSC Adv., 2014, 4, 8421-8430.

47 Y. Lin, C. Xu, J. Ren and X. Qu, Angew. Chem., 2012, 51, 12579-12583.
48 E. Abdelkader, L. Nadjia, B. Naceur, B. Boukoussa, A. Mohamed, Advances in Science, Technology \& Innovation, 2018, pp. 129-132.

49 C. Dai, X. Zhou, Y. Zhang, Y. Duan, Z. Qiang and T. C. Zhang, Environ. Technol., 2012, 33, 1101-1109.

50 E. G. Heckert, S. Seal and W. T. Self, Environ. Sci. Technol., 2008, 42, 5014-5019.

51 M. Sun, G. Zhang, Y. Qin, M. Cao, Y. Liu, J. Li, J. Qu and H. Liu, Environ. Sci. Technol., 2015, 49, 9289-9297.

52 C. Korsvik, S. Patil, S. Seal and W. T. Self, Chem. Commun., 2007, 1056-1058.

53 Q. Yu, R. Zhang, S. Deng, J. Huang and G. Yu, Water Res., 2009, 43, 1150-1158.

54 D. Brooke, A. Footitt, T. Nwaogu and G. Britain, Environmental risk evaluation report: Perfluorooctanesulphonate (PFOS), 2004.

55 K. K. Kefeni, T. A. M. Msagati and B. B. Mamba, J. Cleaner Prod., 2017, 151, 475-493.

56 P. Gao, Y. Ding, H. Li and I. Xagoraraki, Chemosphere, 2012, 88, 17-24.

57 M. Singh and S. Verghese, Int. J. Eng. Sci. Res. Technol., 2016, 5, 150-159.

58 A. K. Slavov, Food Technol. Biotechnol., 2017, 55, 14-28.

59 M. O. Aust, F. Godlinski, G. R. Travis, X. Hao, T. A. McAllister, P. Leinweber and S. Thiele-Bruhn, Environ. Pollut., 2008, 156, 1243-1251.

60 N. Wang, X. Guo, J. Xu, X. Kong, S. Gao and Z. Shan, J. Environ. Sci. Health, Part B, 2014, 49, 468-479.

61 J. R. Danalewich, T. G. Papagiannis, R. L. Belyea, M. E. Tumbleson and L. Raskin, Water Res., 1998, 32, 3555-3568.

62 H. Juretić, G. Smoljanić and M. Barta, Holistic Approach Environ., 2015, 5, 135-149.

63 C. Karaguzel and Z. Xu, Physicochem. Probl. Miner. Process., 2017, 53, 750-757.

64 J. G. Clar, W. E. Platten, E. J. Baumann, A. Remsen, S. M. Harmon, C. L. Bennett-Stamper, T. A. Thomas and T. P. Luxton, Sci. Total Environ., 2018, 613-614, 714-723.

65 EPA, Toxicological review of cerium oxide and cerium compounds, 2009. 